\title{
Método Canguru: a importância da família na recuperação do recém-nascido de baixo peso
}

\author{
Jair Alves Maia \\ Manoel Pereira de Oliveira $^{2}$ \\ Simone de Souza Furtado ${ }^{3}$ \\ Lissiane Matos da Silva ${ }^{4}$ \\ Maria Lucrecia Batista Pereira ${ }^{5}$
}

Recebido em: 08/08/2011
Aceito em: $16 / 11 / 2011$

O Método Canguru é uma assistência neonatal voltada para o atendimento do recém-nascido prematuro que consiste em colocar o bebê em contato pele a pele com a genitora. Este estudo teve como objetivo geral, esclarecer a importância da família durante o período de recuperação do recém-nascido de baixo peso. A metodologia utilizada foi uma pesquisa de caráter descritivo, com abordagem qualitativa. Os dados da pesquisa foram coletados por meio de entrevistas com perguntas abertas, no setor específico "Mãe Canguru" na Maternidade Bárbara Heliodora (MBH) em Rio Branco - AC. A pesquisa teve uma amostra de quinze (15) famílias de ambos os sexos: dez (10) mães e cinco (5) pais, que se encontravam no período de puerpério. Todas as mães tiveram parto prematuro e seus RNs apresentaram baixo peso. Os dados da pesquisa foram obtidos em junho de 2011. Concluiu-se que o MMC é um método simples. No entanto não é devidamente explicado pela equipe. Muitas mães praticam o método, no entanto, sem saber os inúmeros benefícios que ele proporciona.

Descritores: Método Canguru, Baixo Peso, Família.

\section{Kangaroo Method: the importance of family in recovery of babies of low weight}

The Kangaroo Mother Care is a service focused on neonatal care of premature newborns that consists in placing the baby skin to skin contact with the progenitor. This study aimed to clarify the overall importance of family during the recovery period of newborns of low birth weight. This is a descriptive and qualitative research. The data of the research were collected by means of interviews with open questions, in particular sector "kangaroo mother" in the maternity Heliodora Barbara (MBH) in Rio Branco - Acre. There were a sample of fifteen (15) families of both genders: ten (10) mothers and five (5) fathers, who were in the postpartum period. All mothers suffered premature delivery, and their newborns were underweighted. The data of the research were obtained in June 2011. It is concluded that MMC is simple but it is not well explained by the team. Although many mothers practice the method, they don't know the many benefits that the method provides.

Descriptors: Kangaroo Mother Care, Low Weight, Family.

\section{Método Canguro: la importancia de la familia em la recuperacion de los bebés de bajo peso}

El Cuidado Madre Canguro es un servicio centrado en la atención neonatal de recién nacidos prematuros que consiste en la colocación de la piel del bebé en contacto piel con el progenitor. Este estudio tuvo como objetivo aclarar en general la importancia de la familia durante el período de recuperación de los recién nacidos con bajo peso. La metodología utilizada fue un estudio descriptivo con enfoque cualitativo. Los datos del estudio se recogieron por medio de entrevistas con preguntas abiertas, en particular la industria "madre canguro" en la Maternidad Barbara Heliodora (MBH), en Río Branco - AC. La encuesta tuvo una muestra de quince (15) familias de ambos sexos: diez (10) madres y cinco (5) padres, que estaban en el período posparto. Todas las madres tenían un parto prematuro y sus recién nacidos tuvieron bajo peso. Los datos del estudio fueron obtenidos en junio de 2011. Se concluye que la MMC es un método simple. Sin embargo, no se explican adecuadamente por el equipo. Muchas madres practican el método sin conocer los numerosos beneficios que proporciona.

Palabras clave: Cuidado Madre Canguro, Bajo Peso al Nacer, La Familia.

\section{INTRODUÇÃO}

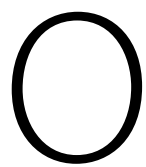
Método Canguru é uma assistência neonatal voltada para o atendimento do recém-nascido prematuro, que consiste em colocar o bebê em contato pele a pele com a genitora ${ }^{(1)}$.

O Método Mãe Canguru (MMC), também conhecido como "Cuidado Mãe Canguru" ou "Contato Pele a Pele", tem sido proposto como uma alternativa ao cuidado neonatal convencional para bebês de baixo peso ao nascer (BPN).
Foi idealizado e implantado de forma pioneira por Edgar Rey Sanabria e Hector Martinez em 1979, no Instituto MaternoInfantil de Bogotá, Colômbia, e denominado "Mãe Canguru" devido à maneira pela qual as mães carregavam seus bebês após o nascimento, de forma semelhante aos marsupiais(2).

O MMC começou no Brasil em 1991, no Hospital Guilherme Álvaro, em Santos, São Paulo. Logo em seguida foi implantado em Recife, no Instituto Materno- Infantil de Pernambuco, e vem

1 Enfermeiro. Especialista em Saúde Pública pela UNINORTE-AC. Gerente de Enfermagem da Saúde Indígena do Acre. Professor do Curso de Enfermagem da UNINORTE-AC. E-mail: jairalvesac@hotmail.com.

2 Acadêmica do Curso de Administração da Faculdade Barão do Rio Branco. Agente administrativo do COREN-AC.

3 Acadêmica do Curso de Enfermagem da Faculdade Barão do Rio Branco.

4 Acadêmica do Curso de Enfermagem da Faculdade Barão do Rio Branco.

5 Enfermeira. Especialista em Enfermagem Obstétrica e em Enfermagem Medico-Cirúrgica pela UFAC. Professora Substituta da UFAC. Conselheira efetiva do COREN-AC do triênio 2009 a 2011. 
sendo utilizado em vários serviços de todo o país. No Hospital Guilherme Álvaro foram utilizados, primeiramente, o espaço e a equipe do alojamento conjunto, até que se dispusesse de instalações próprias e equipe multidisciplinar ${ }^{(3)}$.

A Norma de Atenção Humanizada ao Recém-Nascido de Baixo Peso - Método Canguru, foi lançada em dezembro de 1999 e publicada através da Portaria Ministerial no 693 de 05/07/2000. O Método Canguru passou assim a ser incluído na Política Governamental de Saúde Pública, no Brasil, como um procedimento de assistência médica, com inclusão na tabela de procedimentos do SUS ${ }^{(4)}$.

\section{METODOLOGIA}

A pesquisa ocorreu de forma descritiva, com abordagem qualitativa. Os dados da pesquisa foram coletados através de entrevistas com perguntas abertas, no setor específico "Mãe Canguru" da Maternidade Bárbara Heliodora (MBH) em Rio Branco - Acre, no mês de junho de 2011.

A pesquisa teve uma amostra de quinze (15) famílias de ambos os sexos, sendo dez (10) mães e cinco (5) pais, que se encontravam no período de puerpério, após partos prematuros, com seus RNs de baixo peso, no setor Mãe Canguru da instituição em estudo.

Utilizou-se o questionário como instrumento de coleta dividido em várias perguntas simples e abertas referentes à temática abordada. Além disso, foram analisados os prontuários dos RNs a fim de selecionar apenas os que se encontravam em baixo peso. Realizaram-se entrevistas com famílias de recém-nascidos de baixo peso, tendo como sujeito de estudo: mães e pais de RNs que se encontravam no setor Mãe Canguru da MBH, com o intuito de avaliar através da família o desenvolvimento dos RNs de baixo peso. Os relatos dos sujeitos de estudo foram identificados com letra " $\mathrm{C}$ ", seguidos de algarismos arábicos para manter suas identidades em sigilo.

Os critérios de inclusão utilizados para compor o número de sujeitos de estudo foram: ter mais de 18 anos; mães, pais ou qualquer familiar com vínculo consanguíneo ou afetivo que realizaram o MMC; mães de recém-nascidos de baixo peso ou prematuros; aceitar participar e estar presente no momento da pesquisa.

Em respeito aos procedimentos éticos, obedeceu-se ao preconizado na Resolução 196/96 da Comissão Nacional de Ética em Pesquisa (CONEP), no que diz respeito à pesquisa com seres humanos. A aprovação para realização do estudo foi concedida pelo Comitê de Ética em Pesquisa (CEP) do Hospital das Clínicas do Acre, em 12 de maio de 2011, com o Registro de Protocolo No 587/2011.

Os participantes foram orientados sobre o objetivo do estudo e a importância de sua participação, assim como o direito de não participarem do estudo. Os que concordaram em participar da pesquisa assinaram o termo de consentimento livre e esclarecido.

\section{MÉTODO CANGURU}

A atenção humanizada ao recém-nascido e sua família tem como modelo o Método Mãe Canguru, cujo principal recurso para sua implantação é o afeto que existe entre pais e filhos. $\mathrm{O}$ ato de carregar o bebê contra o peito proporciona aquecimento e estímulo ao recém-nascido, o íntimo contato pele a pele amplia a formação do vínculo e favorece o aleitamento materno ${ }^{(5)}$.

A ideia do MC é a colocação do recém-nascido contra o peito da mãe, que irá promover maior estabilidade térmica. Podendo substituir as incubadoras, permite alta precoce, diminuição da taxa de infecção hospitalar e consequentemente melhor qualidade da assistência com menor custo para o sistema de saúde ${ }^{(6)}$.

O método canguru é desenvolvido em três etapas:

Primeira etapa: refere-se ao período de internação na terapia neonatal. No local da terapia, a família pode receber informações e é preparada para aderir ao mesmo, desenvolvendo o método Mãe Canguru parcialmente;

Segunda etapa: sobre o período em que o neonato, clinicamente estável e com mais de $1.250 \mathrm{~g}$, permanece com a mãe na enfermaria Mãe Canguru de estabilização, desde que ela esteja pronta para recebê-lo;

Terceira etapa: é a fase de acompanhamento ambulatorial para a vigilância do crescimento e desenvolvimento do $\mathrm{RN}$, interação família-bebê e detecção precoce de situações de risco.

Durante uma análise das normas e rotinas definidas pelo Ministério da Saúde identificaram-se cinco pilares na proposta brasileira: cuidados individualizados, centrados nos pais; contato pele a pele precoce; controle ambiental de luz e som; adequação postural e amamentação(2).

\section{PERCEPÇÃO DOS PAIS SOBRE O MÉTODO MC}

A família também é avaliada, pois os pais devem estar seguros, ser capazes de aplicar o método e colocar-se totalmente à disposição para comparecer às consultas regularmente. A família deve ter muita disciplina, compromisso, motivação e disponibilidade, visto que a posição canguru é adotada durante 24 horas. Quando mãe e filho se encaixam no perfil exigido, o bebê recebe alta independentemente do seu peso. A ideia é integrá-lo à família precocemente $\mathrm{e}^{(5)}$.

Esse método apresenta várias vantagens, das quais se destacam o fortalecimento do vínculo entre mãe e filho; o aleitamento materno; a melhora no desenvolvimento físico e emocional do bebê; a redução do risco de infecção perinatal; a melhora na estabilidade térmica e respiratória do recém-nascido; a diminuição do tempo de internação e abandono de bebês prematuros em unidades de neonatologia, além de promover a integração precoce entre o bebê e sua família( ${ }^{(5)}$.

\section{O RECÉM-NASCIDO DE BAIXO PESO}

Os recém-nascidos são considerados de baixo peso quando nascem com peso inferior a $2.500 \mathrm{~g}$. Neste requisito são incluídos tanto os prematuros quanto os recém-nascidos a termo com retardo no crescimento intrauterino ${ }^{(7)}$.

Devido à imaturidade de seus órgãos ou sistemas, o prematuro pode apresentar inúmeros problemas como 
a incapacidade de regular a própria temperatura; a dificuldade de sucção e mais riscos às infecções; hiperbilirrubinemia; apneia; problemas respiratórios, como membrana hialina; hipotermia e hipertermia; hipocalcemia; problemas hematológicos e sangramentos; problemas neurológicos; problemas metabólicos; insuficiência respiratória transitória; displasia broncopulmonar e problemas cardiovasculares ${ }^{(5)}$.

O leite materno é recomendado para todos os RNs, em especial os de baixo peso, por proporcionar uma combinação única de proteína, lipídios, carboidratos, minerais, vitaminas, enzimas e células vivas, constituindo um melhor benefício nutricional para o $\mathrm{RN}$, ajudando-o a constituir os sistemas imunológicos, psicológicos e econômicos ${ }^{(7)}$.

\section{DISCUSSÃO DOS RESULTADOS}

A amostra tem a composição de 15 pais que se encontravam no setor Mãe Canguru da Maternidade Bárbara Heliodora (MBH), sendo $67 \%$ mães e 33\% pais, com a faixa etária entre 18 a 49 anos.

\section{Intimidade entre mãe, pai e familiares com o Método Mãe Canguru}

Essa categoria analisa a relação afetiva adquirida entre mãe, pai, familiares e filho na execução do método canguru, destacando os relatos dos mesmos quanto a essa intimidade obtida na recuperação do recém-nascido de baixo peso.

"Quando eu a toquei, ela acalmou. Acho que me conhece, é a mamãe, agora eu amo minha filha, meu Deus, agora eu amo mesmo." (C1)

"Antes eu não podia nem dar de mamar, acho até que ela tomava leite de outra pessoa, agora eu dou de mamar pra ela, é tão linda (...) tão pequenininha, tão linda (...) ela pode estar chorando, mas, quando eu pego, acabou." (C2)

"Eu tinha vontade de arrancar ela lá da UTI, vontade de arrancar tudo e correr pra casa... queria abraçar, só isso, mais nada... mas agora eu abraço, beijo, abraço, beijo de novo (risos) agora ela morre só se for do cheiro do papai." (C3)

Com esses relatos foi possível observar que a aproximação mãe, pai, familiares e bebê favorece as condições de relacionamento, instituindo credibilidade, confiança e pontos de apoio em momentos difíceis, diminuindo a tensão e a angústia, referendando o cuidado dirigido de forma humana ${ }^{(8)}$.

\section{COMO VEM SENDO O DESENVOLVIMENTO DO SEU BEBÊ?}

Quando questionados sobre a importância do MMC para o desenvolvimento de seu filho, constatou-se que todos os pais relataram a relevância deste método. Podemos perceber, segundo relatos dos familiares, as mudanças nos bebês com o método Mãe Canguru:

"Antes a S. ficava muitíssimo agitada, agora parece que ela está grudadinha em mim outra vez. Quando ela fica só de fralda e eu sem nada na parte de cima, parece que ela gruda, fica bem calminha, e esses dias parece que tudo regulou, a temperatura, a respiração está bem levinha, acho que ela até relaxa." (C1)

"Ajudou bastante, principalmente quanto à regulação da temperatura. As meninas (referindo à equipe técnica) disseram que estava abaixo de $36^{\circ} \mathrm{C}$, mas que agora está mantendo $37^{\circ} \mathrm{C}$ o tempo todo." (C2)

Percebe-se, com os relatos, a importância do contanto pele a pele precoce entre mãe, pai, familiares e bebê e de como ela é favorável ao desenvolvimento do mesmo. Além de criar condições de relacionamento, essa aproximação estabelece credibilidade e confiança, diminuindo angústias. O suporte familiar é de fundamental importância para a recuperação do bebê, pois é necessário que a mãe tenha amor, confiança e disponibilidade de tempo para se dedicar integralmente ao bebê e, dia após dia, vivenciar e contribuir para sua evolução.

Segundo Charpak ${ }^{(8)}$, a família substitui a incubadora, uma vez que o MMC é geralmente estabelecido onde há recursos técnicos e humanos exigidos para garantir a boa evolução do RNBP. Esse cuidado vem favorecer o maior contato entre mãe e bebê, propiciando assim momentos prazerosos entre mãe e filho, revigorando a formação do vínculo, desviando problemas emocionais e cognitivos ocasionados pela separação dos mesmos.

A partir das falas das mães e dos pais, podemos perceber as mudanças ocorridas na vida desses recém-nascidos após a internação no alojamento conjunto do Método Mãe Canguru.

"Antes ela nem se mexia, agora eu nem acredito, na hora de dar o banho e trocar de fralda então... é uma luta (risos), nem acreditava mais que ia ver ela assim." (C1)

"Mal abria os olhos, agora só quer viver no peito, né, neném (...) foi só fé em Deus mesmo, sem ela nem sei, a médica me disse que eu tinha que ter cuidado porque ela é prematura e o pulmãozinho é fraquinho, mas a respiração dela está bem agora." (C2)

"Meu filho é perfeito, cada dia ele melhora mais, cada dia as meninas (se referindo à equipe) dizem que melhorou em alguma coisa, um dia é a respiração, outro dia é a temperatura, outro dia é o peso, cada dia é uma surpresa, né, meu amor." (C3)

As vantagens do MMC são: alta hospitalar precoce, aumento da possibilidade de sobrevivência do bebê, diminuição do tempo de separação, redução no índice de abandono, diminuição de infecções hospitalares, diminuição de custos hospitalares, estimulo ao aleitamento materno, vinculo afetivo mãe-filho adequado ${ }^{(9)}$.

\section{Você concorda ou não com o Método Mãe Canguru?}

Quando abordadas sobre se concordam com o método Mãe Canguru, as entrevistadas relataram em síntese não gostar nem concordar com ele. Como podemos ver a seguir:

"(...) Não concordo porque é muito chato, mas ela tá melhor, tá abrindo até os olhos." (C1)

"É chato porque não tem hora certa pra fazer e, quando a gente faz, sempre tem um pra atrapalhar, os médicos nunca têm hora certa pra vir, às vezes eu acabo de colocar...e lá vem um..." (C2)

Foi possível observar com esses relatos que, por mais que a equipe esteja empenhada em oferecer suporte técnico e emocional, falta organização para que o MMC obtenha $100 \%$ de aprovação. 


\section{PRÓS E CONTRAS DO METODO MÃE CANGURU}

Em relatos dos entrevistados sobre os prós, percebe-se que o ponto chave é o fato de a mãe ou o pai poder ficar junto do recém-nascido, ser responsável pelos cuidados do seu bebê.

“(...) ele ficava lá (refere-se à UTI), dava uma tristeza (choro), agora ele tá aqui, eu tô cuidando dele, nem acredito, mas tápassando, nós estamos vencendo. (C1)

"(...) agora a mamãe e o papai cheiram (falando com o bebê e acariciando-o), a mamãe e o papai pegam, a mamãe dá banho, tudo a mamãe e o papai, tudo (...) até comidinha é no peitinho da mamãe." (C2)

"Antes eu não ligava muito, eu tinha medo, ia ver ela uma vez só por dia, nem pegava, eu tinha muito medo, agora olha aqui a princesa, nem parece que eu faço tudo isso (referindo-se aos cuidados), pega avó, pega neném, agora é a sua vez de colocar aí (referindo-se ao canguru)." (C3)

Outro ponto fraco do MMC é o fato de ficarem longe de casa e de seus familiares. A permanência prolongada no ambiente hospitalar gera alguns conflitos para os casais ${ }^{(10)}$.

\section{CONSIDERAÇÕES FINAIS}

Ao final da pesquisa sobre a importância da família na recuperação do RN de baixo peso no alojamento Mãe Canguru da $\mathrm{MBH}$, foi possível concluir que a idade das mães entrevistadas não foi um fator condicionante que culminou no parto prematuro, visto que menores de 18 anos e maiores de 35 são mais propícias a esse fato. Porém, fatores como hipertensão e infecção urinária foram os mais identificados como causa do parto prematuro.

Analisando os dados coletados, percebe-se que para as entrevistadas o MMC configura-se como um método muito simples, mas que não é bem explicado pela equipe. Muitas mães o adotam, mas sem saber os inúmeros benefícios que o método traz. Foi possível observar que o contato pele a pele no binômio mãe e bebê gera sentimentos de imenso amor e fortalecimento do vínculo afetivo, fato este essencial para o desenvolvimento do bebê, aumentando consideravelmente a intimidade entre ambos, contribuindo portanto para a diminuição de abandono e maus tratos.

Quanto à importância da família para o desenvolvimento do recém-nascido de baixo peso, todas as participantes que concordaram com o MMC perceberam uma evolução clínica considerável, através de reações observadas pelas mães após o método. Dentre elas, incluem-se respostas motoras pelo estímulo auditivo provocado pela mãe, como bebês agitados que, após a adoção do método, tornaram-se bem calmos, melhorando a frequência respiratória e cardíaca. O mais importante para as mães foi o fato de poderem se dedicar aos seus RNs de forma integral, tornando-se responsáveis pela evolução de seu bebê. O ponto mais gratificante para ambos foi no momento da alta hospitalar, onde elas perceberam que são indispensáveis na recuperação de seu bebê. O pai, por sua vez, deve ser instigado a participar ativamente do cuidado do RN, sempre que possível, mas não apenas ele, pois todos os parentes consanguíneos desempenham função importante na prática do MMC.

De acordo com o presente estudo foi possível observar que o MMC não existe e não funciona sem a participação da família. Somente ela fornece uma assistência humanizada e perfeita na sua totalidade, por proporcionar um cuidado não técnico, mas com amor. Por mais que a equipe esteja empenhada em oferecer os melhores cuidados, apenas a família proporciona um cuidado em tempo integral e personalizado para os recém-nascidos no Método Canguru.

\section{Referências}

1. Ministério da Saúde (BR). Secretaria de Políticas de Saúde. Área de Saúde da Criança. Atenção humanizada ao recém-nascido de baixo peso - Método Mãe Canguru: manual do curso. Brasília: Ministério da Saúde; 2004.

2. Venâncio Sl, Almeida H. Método Mãe-Canguru: aplicação no Brasil, evidencia cientificas e impacto sobre o aleitamento materno. J Pediatr (Rio J.). 2004;80(5 Supl.):S173-S80.

3. Cardoso ACA, Romiti R, Ramos JLA, Issler H, Sanches MTC. Método Mãe-Canguru: aspectos atuais. São Paulo: Departamento de Pediatria da Faculdade de Medicina da Universidade de São Paulo; 2006.

4. Lamy ZC, Gomes MASM, Gianini NOM, Hennig MAS. Atenção humanizada ao recém-nascido de baixo peso: Método Canguru; a proposta brasileira. Ciênc Saúde Coletiva. 2005;10(3):659-68.

5. Silva FF, Prado SRA. Método Mãe-Canguru: um novo paradigma na assistência ao recém-nascido e sua família. Rev Enferm UNISA. 2003.

6. Neves PN, Ravelli APX. Método Mãe-Canguru: percepções de puérperas [monografia]. Ponta Grossa: Universidade Estadual de Ponta Grossa; 2010. 7. Ministério da Saúde (BR). Secretaria de Políticas de Saúde. Área de Saúde da Criança. Atenção humanizada ao recém-nascido de baixo peso - Método Mãe Canguru: manual do curso. Brasília: Ministério da Saúde; 1999. 8. Charpak N, Figueroa CZ. O Método Mãe-Canguru - pais e familiares dos bebês prematuros podem substituir as incubadoras. Rio de Janeiro: McGraw Hill; 1999. 9. Lana APB. O livro de estímulo à amamentação - uma visão biológica, fisiológica e psicóloga - comportamental da amamentação. São Paulo: Atheneu; 2001. 10. Guimaraes GP, Monticelli M. A formação do apego pais/recém-nascido pré-termo e/ou baixo peso no Método Mãe-Canguru: uma contribuição da enfermagem. Rev Gaúch Enferm. 2006. 